\title{
GENESIS
}

\section{A Rede Ibero Americana de Educação Artística: Um projecto para construir caminhos comuns}

\section{Teresa Torres Eça Fernando Hernández}

\section{RESUMEN}

En la ruta de la educación artística extraída de las conclusiones de la Conferencia Mundial sobre la Educación Artística de UNESCO celebrada en Lisboa en 2006 se declaraba que era necesario "crear redes de cooperación entre los Estados miembros y entre sus respectivos sistemas de educación y cultura, con el fin de desarrollar la educación de las artes y alianzas de cooperación ". De hecho, las redes más que otro tipo de asociación facilitan la preparación y puesta en marcha de proyectos regionales e internacionales de investigación y educación. Mucho antes de la conferencia de la UNESCO, un grupo de investigadores y profesores de artes soñaba con la creación de la Rede Iberoamericana de Educación Artística, acreditando que esta red intercontinental facilitaría la cooperación y el intercambio de buenas prácticas en educación artística fomentando la participación de los profesores de artes a nível, nacional e internacional para adquirir mayor representatividad social y competencia profesional.

\section{ABSTRACT}

The arts education roadmap written after the conclusions of the UNESCO World Conference on Arts Education held in Lisbon in 2006 stated that it was necessary to "create networks of cooperation between Member States and between their respective systems of education and culture, in order to develop successful arts education activities and alliances of cooperation '. In fact networks more than other type of associations facilitate the design and development of regional projects and promote international research in education. Several years before the Unesco conference a group of researchers and teachers dreamed about creating the Ibero American Arts Education network, believing that it would build intercontinental links and enable regional cooperation by sharing good practices and strategies for arts education. The network was intended to encourage art teachers to make alliances nationally and internationally, acquire greater social significance and professional competence.

\section{RESUMO}

O Roteiro sobre a Educação Artística redigido a partir das conclusões da Conferência Mundial sobre Educação Artística da UNESCO, realizada em Lisboa em 2006, referia que era necessário "Criar redes de cooperação entre os Estados Membros e entre os seus respectivos sistemas de educação e de cultura, com o objectivo de basear o desenvolvimento bem sucedido da Educação Artística em actividades e alianças de cooperação" ${ }^{1}$. De facto as redes mais do que outro tipo de associação facilitam a preparação e o lançamento de projectos regionais e internacionais de educação e investigação e foi por isso que bem antes da conferência da Unesco um grupo de investigadores e professores sonhou a criação da Rede Ibero Americana de Educação Artística, sentindo que construir esta rede intercontinental facilitaria a cooperação regional e a partilha de boas práticas na concretização de estratégias de Educação Artística e que poderíamos encorajar a participação e a organização dos professores de arte, a nível nacional e internacional, para que adquiram maior representatividade social e competência profissional.

1 Documento traduzido para português acessível em: http://www.apecv.pt/index. php?option=com_content\&task=view\&id=129\&Itemid=67

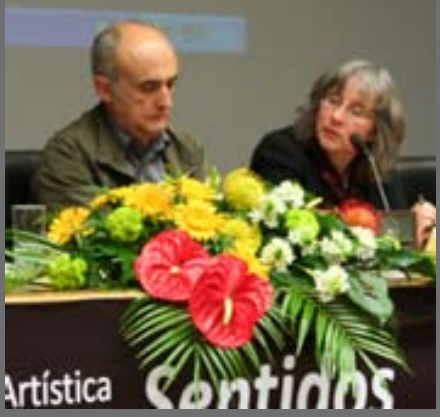




\section{OS PRIMÓRDIOS DA REDE}

A concepção da rede demorou sete anos, entre um primeiro Congresso Ibérico de Educação Artística e um primeiro Congresso Ibero-Americano de Educação Artística. Entre um e outro sucederam-se encontros e descobertas. Mas, ao longo desse tempo, foi crescendo sobretudo a necessidade de estabelecer vínculos, aproveitando as potencialidades da partilha do proporcionada pelas nossas línguas ibéricas, começando a construir um projecto de rede que nos permitisse levar a cabo projectos de intercâmbio, que nos possibilitasse aprender uns com os outros, construir um diálogo que seja alternativo às vozes hegemónicas no âmbito da Educação nas Artes. As páginas que se seguem, escritas a quatro mãos, pretendem ser o primeiro esboço de esse itinerário que estamos a começar.

Os autores deste artigo coincidiram pela primeira vez em Poznan, na Polónia em Junho de 2000, no 5o congresso da International Society for Education Through Art (InSEA). Nessa altura, tanto um como outro tentávamos compreender, para pôr em prática, como poderiam funcionar as redes profissionais e científicas em contextos locais e internacionais. No caso da Teresa, esta já fazia parte da APECV (Associação de Professores de Expressão e Comunicação Visual), Portugal, e da InSEA; por seu lado Fernando, estava também vinculado à InSEA (tanto na organização internacional como na sua versão espanhola, AEEA) e desde 1993 à NAEE (a Associação de Educadores de Arte dos Estados Unidos). Ambos partilhávamos a sensação dos limites que nos ofereciam tanto a APECV como a AEEA, nesse momento tínhamos a impressão de que a InSEA era demasiado anglófona para as nossas inquietações. A Teresa recorda, o seguinte dos nossos primeiros encontros:

"En Poznan o Fernando Hernandez sentou-se ao meu lado e disse-me: "Temos que fazer alguma coisa". Passado pouco tempo voltei a encontrá-lo durante as IV Jornadas de Historia de La Educación Artística, em Girona, e de novo ouvi uma voz que me dizia "temos que fazer alguma coisa".

Enraizados nestes primeiros encontros fomos aproximandonos da realidade da Educação das Artes nos nossos respectivos países. Por exemplo a Teresa, nas Jornadas de Girona deu-se conta do peso que tinha a educação artística na Cata- lunha, da força da investigação que se estava a desenvolver na Universidade de Barcelona e de Girona, da capacidade de mudança que estava a assistir.

Esta observação permitiu-lhe, por comparação, fazer um primeiro balanço da Educação das Artes em Portugal.

“No meu país a educação artística nem sequer tinha campo, havia um moribundo movimento português de educação pela arte, herança de Arquimedes da Silva Santos, de influencia vagamente Readiana e uma associação profissional com interesses mais práticos do que científicos. As Universidades nem queriam saber de educação artística e as Escolas Superiores de Educação estavam a enviar os seus professores para cursos no estrangeiro. A investigação que existia reduzia-se a algumas teses de mestrado e doutoramento na sua maioria pesquisa histórica e a experiências didácticas pontuais patrocinadas pelo Ministério da Educação ou pela Fundação Calouste de Gulbenkian".

“Naquela altura havia muitas pessoas em Portugal que acreditavam na força da educação artística e que estavam a dar o seu melhor para tornarem o campo mais visível, mas estavam muitos separados e trabalhavam muito sozinhos. A divulgação do que se estava a produzir era muito fraca. Os educadores que tinham ido tirar cursos de doutoramento ao estrangeiro estavam a regressar mas não se estavam a agrupar ou a partilhar as suas perspectivas, pelo contrário fechavam-se dentro dos muros das suas universidades e escolas".

A visão do Fernando sobre a Educação das Artes em Espanha não era tão optimista como a que a Teresa tinha tido nesse primeiro encontro em Girona:

"Se bem que a Educação das Artes, especialmente aquela veiculada às artes visuais, tinha no início do século XXI presença em quase todas as universidades espanholas, sobretudo nas Faculdades de Educação, e em algumas de Belas Artes, o seu reconhecimento não deixava de ser residual. 0 professorado dedicado à formação de docentes debatia-se com a revindicação de um especialista nas artes visuais para a escola primária, que nunca chegou. Enquanto nas faculdades de Belas Artes se mantinha um esforço constante para não serem excluídos das instituições, embora a sua primeira 
finalidade fosse formar artistas, a maioria dos estudantes (cerca de 65\%) acabava por se dedicar à docência no ensino secundário".

Mas no horizonte apareciam sinais de mudança:

“Também era certo que a pouco e pouco se ia tecendo uma rede entre algumas universidades que terminaria com a concessão da menção de qualidade ao programa de doutoramento "Artes Visuales y Educación: un enfoque construccionista", ao qual se vincularam as universidades de Granada, Barcelona, Sevilha e Girona. Esta relação foi permitindo ir consolidando uma serie de linhas de investigação (com as teses doutorais correspondentes) que, embora nem sempre, se viram reflectidas em publicações, permitindo consolidar um reconhecimento nas instituições de referência e na comunidade internacional".

“O meu conhecimento da situação da Educação das Artes em Portugal era baseado nas minhas permanências na Universidade de Évora, a convite do professor Leonardo Charreu, que tinha realizado o seu doutoramento em Barcelona, por quem soube da situação do ensino secundário e também graças a outra tese de doutoramento, de Maria da Conceição Fernandes Ramos, e por outros trabalhos que tinha lido na revista da APECV: Imaginar. Entre uns e outros a minha imagem era difusa, embora visse sinais de esperança".

Com estes antecedentes ambos reconhecíamos que a ligação entre Portugal e em Espanha no que respeita à educação artística em era muito ténue. Talvez por isso quando Teresa propôs à APECV realizar o 1ํ Congresso Ibérico de Educação artística a ideia foi recebida com entusiasmo pelos colegas. Em Novembro de 2001 realizou-se finalmente o 1o Congresso Ibérico de Educação artística, no ISMAI, na Maia, no norte de Portugal. Foi aí que a primeira rede nasceu!

A Rede Ibérica de Educação Artística nasceu numa discussão acalorada sobre a necessidade de maior partilha, maior divulgação, maior proximidade entre professores, educadores e investigadores de educação artística na Península Ibérica. No princípio seríamos talvez umas vinte pessoas a fazer parte da rede, um grupo virtual construído no Yahoo Groups. Claro que o Yahoo não foi a melhor escolha. Cada vez mais nos convencemos que por questões éticas deveríamos ter feito a rede num servidor da Internet isento de censura ou trocar para uma plataforma virtual de software livre. Mas na altura foi o meio encontrado mais fácil de manusear e acessível a todos.

Depois a rede foi crescendo, cresceu tanto que já não fazia sentido chamar-se apenas ibérica, pois tinha pessoas de pelos menos dois continentes usando línguas muito parecidas: o português e o espanhol. Em 2007 convencemo-nos que deveríamos alargar tanto os horizontes como as metas e juntos preparámos o 10 Congresso Ibero Americano de Educação Artística, numa pequena cidade a sul de Portugal: Beja. A cidade foi escolhida precisamente por ser pequena e por ser do sul, na sua calmaria poderíamos pensar melhor a mudança para a segunda rede: a Rede Ibero-Americana de Educação Artística.

\section{A CONSTRUÇÃO DA REDE}

A Rede foi pouco a pouco ganhando forma e sustentação tentando equilibrar-se entre pólos bem diversos. Foi constituída primeiro através do grupo da Internet ${ }^{2}$, por parceiros de vários países de língua hispânica e lusitana, e visou a promoção e apoio da educação artística possibilitando a partilha de trabalhos, experiências e investigações em Português ou Espanhol. Pretendíamos usar o direito de transmitir o conhecimento nas nossas próprias línguas e evitar hierarquias linguísticas que nos têm relegado para uma posição de subordinação perante aqueles que só falam inglês. Esta declaração de intenções foi o ponto de arranque para os trabalhos futuros. Durante o Congresso de Beja um grupo de trabalho preparou o resto. Decidiu-se que teria uma estrutura rizomática, móvel, organizada a partir de nós tanto geográficos, como temáticos. E acentuou-se o seu carácter de rede livre, independente, onde cada espaço de grupo poderia funcionar autonomamente. A sua função seria a de criar instrumentos para recolher as inquietudes no âmbito da Educação Artística, Arte Educação e Educação para a Cultura Visual.

Os Espaços de encontro da rede foram definidos na altura: o espaço do portal ${ }^{3}$; uma revista on-line, e congressos trienais.

2 http://groups.yahoo.com/group/redibericaedart/

3 http://www.rede-educacao-artistica.org/ 


\section{O PORTAL}

O Portal está a ser construído pelo Laboratório de Arte e Comunicação Multimédia da Escola Superior de Educação de Beja sob a coordenação de Aldo Passarinho. Estará pronto no final de 2009 e oferecerá uma plataforma de acesso ao que se produz na rede, pelos seus membros: blogs, páginas web, centros educativos, fórum de debates, sites de congressos, etc. O portal terá como finalidades:

- dar visibilidade ao que fazem os seus membros (aproveitar o saber expandido);

- divulgar produções (pesquisas, projectos);

- compartilhar ligações;

- compartilhar experiências educativas importantes;

- dialogar.

A Revista: IN-VISIBILIDADES: Revista de pesquisa em educação, cultura e artes.

A presente revista IN-VISIBILIDADES foi preparada por uma equipa formada por Jurema Sampaio; Ricardo Reis; Olaia Fontal; Irene Tourinho e Olga Lucia Olaya. Pretende-se que responda à necessidade que temos de revistas de divulgação de pesquisa, ambicionando ser uma revista de referência no contexto americolatino e que marque posição no mundo da educação artística. Será uma revista científica com revisão de artigos por par académico, e tem formato digital para ser distribuída pela Internet em regime de Copyleft.

\section{OS CONGRESSOS}

Decidiu-se que seria importante continuar a realização de congressos, de três em três anos. Falou-se também em fazer congressos menos formais com mais espaço para o diálogo e para outras linguagens artísticas e outros tipos de actividades.

\section{OS PRESSUPOSTOS DA REDE}

A rede propõe uma resistência activa para criar outra narrativa de escola e da educação artística em todas as frentes das comunidades onde nos inserimos. Aposta na educação artística como elemento de transformação social.
Tal como foi dito no congresso Ibero Americano de Educação Artística, precisamos pensar os tempos e os espaços onde e como possamos estar presentes, temos que nos tornar visíveis, temos que trabalhar em todas as frentes: nas escolas, em todos os níveis de ensino, nos museus, em centros culturais, com as comunidades, nas mudanças de baixo para cima, no processo artístico como processo de investigação, .... Reconhecemos que as nossas estratégias de actuação são com frequência demasiado passivas, defensivas, baseadas em práticas sem contexto. Temos de afrontar o risco e o perigo se sermos ignorados, se calhar já nem nas margens existimos, estamos de fora do discurso educativo e nem nos demos conta disso. A rede servirá para que também nós estejamos convencidos da nossa importância e do papel essencial da educação artística para a sociedade.

O Congresso Ibero Americano de Educação Artística proporcionou uma amostragem das dificuldades que enfrentamos e das realidades que temos. Existem relações tensas entre a teoria e prática; entre o internacional e o local; entre identidade e diversidade; entre conhecimento académico e prático. No entanto tais tensões são geradoras de um diálogo construtivo, podem promover a crítica. Vimos nesse congresso abordagens muito diferentes, constatámos um consenso sobre o âmbito e necessidade da educação artística /arte educação mas um desacordo sobre as designações a adoptar. Surgiu, no congresso, a par da tendência para a narrativa da educação artística como pedagogia da aprendizagem cognitiva, uma grande tendência para a narrativa da educação artística como pedagogia da expressão, do lúdico, centrada na produção de experiências. Vimos também como outras narrativas centradas na arte educação, pratica artística e comunidade podem ser válidas. Com Ana Mae Barbosa apreciámos como era importante atender às necessidades locais, à abordagem da teoria como consciência da prática, e ao sentido de pluralidade,

\section{O FUNCIONAMENTO DA REDE}

A Rede funciona com as pessoas, funciona sobretudo com a vontade das pessoas, ela só existirá enquanto houver vontade e crítica. Vontade para reflectir e partilhar opiniões e 
disponibilidade para criticar a informação que se vai espaIhando. É muito simples.

A Rede funciona com educadores que saibam ser críticos e subversivos, que saibam urdir projectos identitários fazendo conexões com projectos alheios. Porque toda a esperança está nos educadores, eles são capazes de oferecer muito mais do que recebem, sem pretensões de artistas, sem pretensiosismo professoral, não pretendem dar lições a ninguém. $O$ seu objectivo principal é a partilha das suas experiências para construir um colectivo.

As estruturas da rede estão a ser montadas, precisarão da ajuda de tod@s para serem eficazes. Algumas perguntas vão ficar por responder: Como poderá continuar a partir de aqui? Qual o papel da Rede no campo da educação artística e cultural em contextos ibero americanos? Qual o papel da rede em contextos de investigação sobre educação artística e cultural? Qual o impacto da rede junto das forças que determinam políticas e práticas de educação artística e cultural? Como conseguir que a Rede não seja só um espaço de intercâmbio de actividades e informações e se converta num lugar de criação de massa crítica? Como conseguir que a Rede seja um espaço de debate no qual se considere a discrepância como uma riqueza e uma expressão da democracia que nos permite aprender?

Deixemos ao tempo o direito de resposta e a todos nós a responsabilidade de as construir. Algo que só se poderá levar a cabo contando com a generosidade, a exigência crítica e o desejo de aprender com uns e com os outros. 